\title{
Science, research and innovation, essential elements in the economic evolution of the European Union
}

\author{
Constantin Anghelache ${ }^{12}$, Mădălina-Gabriela Anghel ${ }^{2}$, and Ștefan Virgil Iacob $^{2 *}$ \\ ${ }^{1}$ Bucharest University of Economic Studies, Department of Statistics and Econometrics, 15-17 Calea \\ Dorobanti, Bucharest, Romania \\ ${ }^{2}$ Artifex University of Bucharest, Department of Finance and Accounting, 47 Economu Cezarescu \\ Street, Bucharest, Romania
}

\begin{abstract}
The European Union has development programs to ensure the economic growth of the European Union. Member States are going through a deep health and economic and financial crisis with greater effects than in 1929-1933. The elements underpinning Community programs must be based on research and innovation. Increased funding for education, research and innovation is needed. The aim of the research is to highlight the need for sustained efforts to overcome the current situation affecting the world economy and the economy of each country individually. In the study we used statistical-econometric methods, which by analysing and interpreting the data we have to highlight the need for immediate action of concrete measures. In this direction, the data available to us show that the European economy cannot adjust without focusing on innovation, which must accompany high-quality education, coupled with in-depth research. From this perspective it follows that attention must be paid to putting innovation at the heart of high quality education and research. Only on the basis of this fulfilled goal can we think that the European Union will be able to find its bed and move immediately to economic recovery, which will ensure a sustainable economic and social development.
\end{abstract}

\section{Introduction}

The evolution of the European Union is the number one (main) goal of all community development programs. From this point of view, the programs and objectives set by the European Union are primarily aimed at raising science, research and innovation to a higher level, a context in which new projects, achievements of science and technology, are applied in the economic field. This is the guarantee that the realities will be much higher than the current situation.

In programming these future development strategies, the European Union and its Member States must start from the realities of this moment in which the world economy, the Community and each Member State are seriously affected by the deep pandemic and

\footnotetext{
* Corresponding author: stefaniacob79@yahoo.com
} 
economic and financial crisis. Experts estimate that this crisis is much deeper than the great crisis of 1929-1933, and the period of perpetuation is difficult to anticipate and predict at this time. Incidentally, the complication of the pandemic crisis by the emergence of new strains, by trying with modest results so far to eliminate the possibilities of slightly diminished infection will have a negative effect for a longer period of time.

The European Union has become involved in wanting to help the Member States that have suffered, all but in different proportions, due to the pandemic and economic and financial crisis. Recovery and resilience funds aim precisely at the prospect of Member States being helped to channel these additional amounts into the financing of activities that produce gross value added and therefore increase Gross Domestic Product.

Science, research and innovation are the key elements that must underpin the economic development of the European Union. Each Member State must structure its own development strategy for the development and improvement of science, research and innovation, so as to move towards the modernization of national economies as a whole and thereby initiate sufficiently well-developed development projects point, and the results should be reflected in what is obtained measured by the Gross Domestic Product of each country.

Of course, the basic element of science, research and innovation is that in the national economy must be selected those areas in which there are specialists, there is a positive past, based on which research can advance and new technologies emerge, based on which to achieve the development of the economy as a whole and why not, of all the structural elements that are sources of growth of the Gross Domestic Product.

When we said that these three elements, science, research and innovation are essential elements in the economic evolution of the European Union and the Member States each, I started from the fact that the economy today is easily destructured, destabilized by the effects of the pandemic and economic crisis financial. From here we must start reorienting science, research and innovation towards new projects, projects based on the latest methods and possibilities for improvement, such as digitization, robotics, nanotechnology, logical economy and correlation of evolutions as required by the market economy.

The possibility of responding by tender to the demand that the branches of the national economy envisage for the next period cannot be omitted from this analysis either. The projects that will be initiated will also have to be carried out in full cooperation between the Member States and thus ensure that the standard of the economy is raised to clearly higher levels.

\section{Literature review}

Anghelache, Anghel, Dumitrescu and Avram [1] highlighted elements of Romania's strategy and policy in the field of industrial research, technology and innovation, in the general context of the Horizon 2020 development program of the European Union. Anghel, Anghelache and Dumitrescu [2] analysed the evolution of the financial market and the corresponding priorities established by the Partnership Agreement signed between Romania and the European Commission. Anghelache, Anghel and Dumitru [3] highlighted the priority role that research and development should play in the national economy, which should be stimulated and accompanied by increasing allocations from the state budget, in accordance with the provisions of the directives European Union. Bravo-Ortega and Marin [4] analysed the correlation between research and development and productivity. Dachs and Pyka [5] studied the influencing factors of innovation internationalization. Maxwell et. al. [6], as well as Levratto and Tessier [7] analysed the concept of business angels and its role as a source of financing the company. Moncada-Paternò-Castello et al. [8] addressed a number of issues related to the existing corporate research and development 
system in the European Union, compared to the one outside the EU, in terms of performance. Onetti et al. [9] highlighted a series of competitive business models for new companies, based on technology. Pinto [10] focused on the analysis of the characteristics of innovation diversity within the European Union. Srholec [11] studied the effect of foreign ownership on innovation cooperation.

\section{Methodology, data, results and discussions}

The field of science, technology and innovation covers a sufficiently important range in European Union statistics, and in this respect, the development of innovation, science and technology also requires a better and more consistent use of human resources. Also, science is part of the development of society and practically only through the development of science, ie innovation, inventions, in all fields the foundation for the economic progress of each country is provided.

The European Union has supported research and innovation over time, with many prestigious and cost-effective projects in the industrial, biological, pharmaceutical, telecommunications or aerospace fields. Research and development is always considered the spearhead behind economic growth and job growth both in the field of creation and in the field of economic activity. Also, the extension of the influence of research in the field of economic sphere ensures a protection of the environment, of the international business environment, of the improvement of the quality of products made in all fields, especially in the field of medicine, which ensures a much higher health of people in each country.

From October 2010, the European Union launched the development program until 2020, called the Innovative Union, and aimed to develop the research climate in the fields of energy, food security, health and quality of life. Thus, innovations are monitored and implemented through this innovative Union. In this field, countries that are not members of the European Union have been and are also attracted, taking into account, on the one hand, the possibility of attracting other countries to the European Union, or attracting other specialists to research and innovation projects, other countries, which have a tradition in this field.

One of the key objectives of the European Union's strategy to increase research and development is funding, and consequently the strategy set for the period 2010-2020 has targeted long-term objectives which envisaged a 3\% annual increase in funding in this area domain. Also, the overall expenditures in this field of research and development amounted to 284 billion euros in 2014, representing an increase of $3.4 \%$ compared to the previous year, being $42 \%$ higher than in 2004 research and development, the European Union intends to increase labour productivity in this way, to increase the number of jobs offered to the population, so that the concrete result of the increase of the Gross Domestic Product to ensure the possibility of an improvement of the evolution conditions further the economy as a whole, as well as the increase in living conditions, ultimately the quality of life. Regarding the use of research results, the development and growth of the Gross Domestic Product in most European Union countries has been ensured, with a higher emphasis in some Eastern and even Central European countries, which have had a lower level of development, but which by accessing the results of the research have acquired a more intense growth.

Figure 1 shows the shares of research and development expenditures in Gross Domestic Product for the period 2008-2018. 


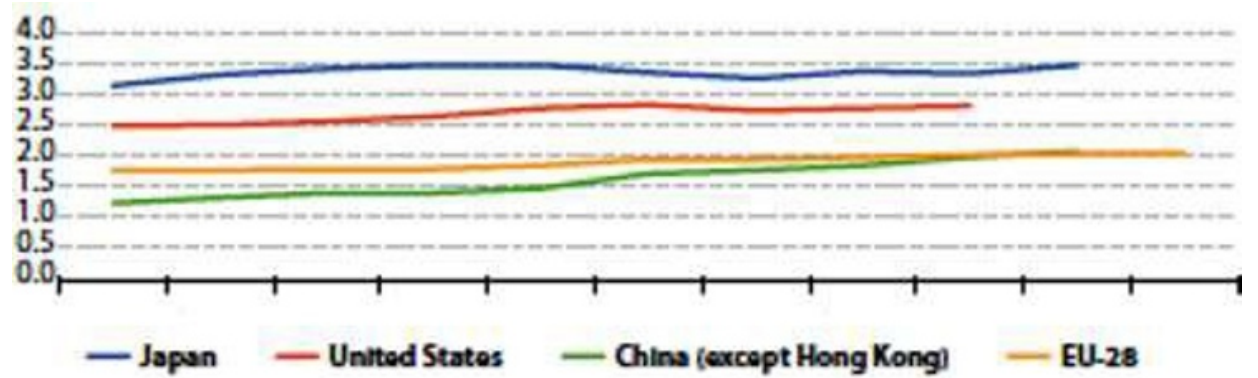

Fig. 1. Weights of R\&D expenditure in Gross Domestic Product for the period 2008-2018. Source: Eurostat (data processed by authors).

Interpreting the data contained in Figure 1, we find that in 2012 there was an increase of $2.01 \%$ compared to 2010 , and in 2013 of $2.03 \%$ compared to 2012 . Also, in

$2014,2015,2016,2017,2018$ registering in principle the same growth rate, 2.10$2.20 \%$ compared to previous periods.

Regarding the increase in research and development spending in the European Union compared to Japan, the United States and China (excluding Hong Kong), we find that the highest growth rate of research and development was recorded by Japan, which had an increase of 3.1\% in 2008, remaining at 3.5-3.6\% in 2013, 2014 and 2015. The United States also followed the same trend in GDP spending, reaching 2\%., 0-2.1\% in 2016, 2018. China, in turn, registered an increasing rate, especially since 2008, being at the same level of the allocation of the Gross Domestic Product equal to that of the United States of America. The European Union has followed an almost constant trend, reaching $2 \%$ in the last four years. During the period under review, the Member States of the European Union paid close attention to increasing the Gross Domestic Product allocations for research and development.

Figure 2 shows the evolution of gross domestic expenditure on research and development in relation to Gross Domestic Product in the period 2008-2018, by performance sectors.
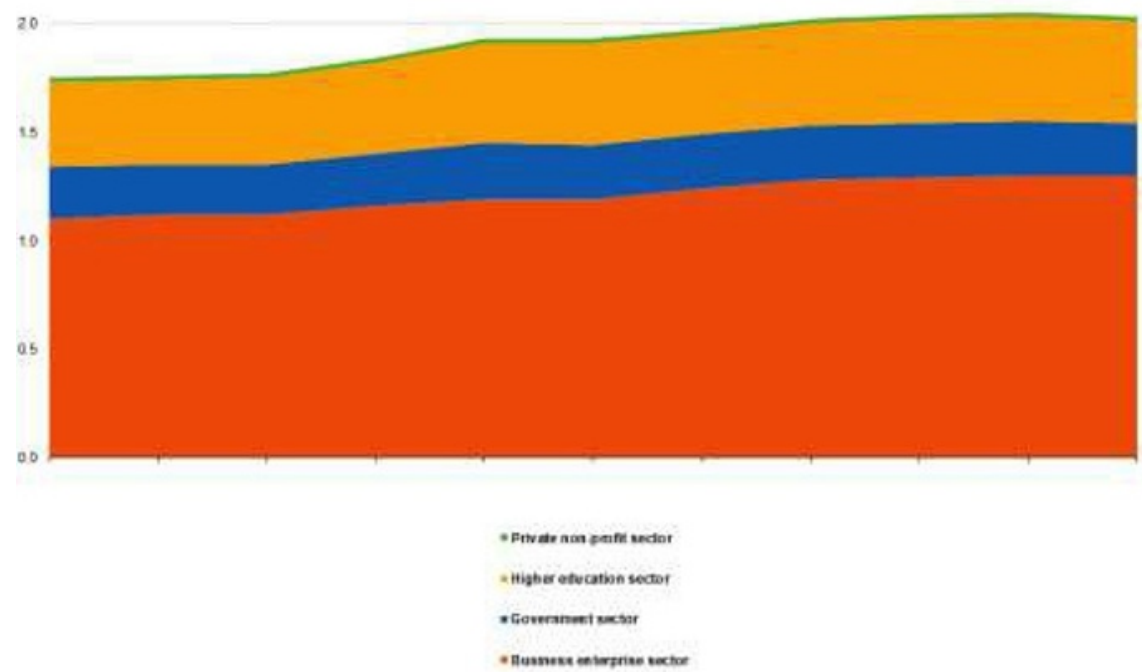

Fig. 2. Gross domestic expenditure on research and development in relation to Gross Domestic Product, by performance sector, EU-28, 2008-2018 (\%). Source: Eurostat (data processed by authors). 
It is found that there has been a high rate of GDP use of R\&D for each performance sector in the period 2008-2018.

An essential element in achieving the improvement of research and development is the number of researchers, innovators, who are attracted in these areas of utmost importance, for the development of research results in the European Union. Thus, the number of researchers in the European Union has increased over the years and in terms of staff involved in these activities, we find that $48 \%$ were concentrated in research in the field of business, higher education, or other important sectors within national economy.

Figure 3 shows the share of the full-time employment rate, with a research employment contract.

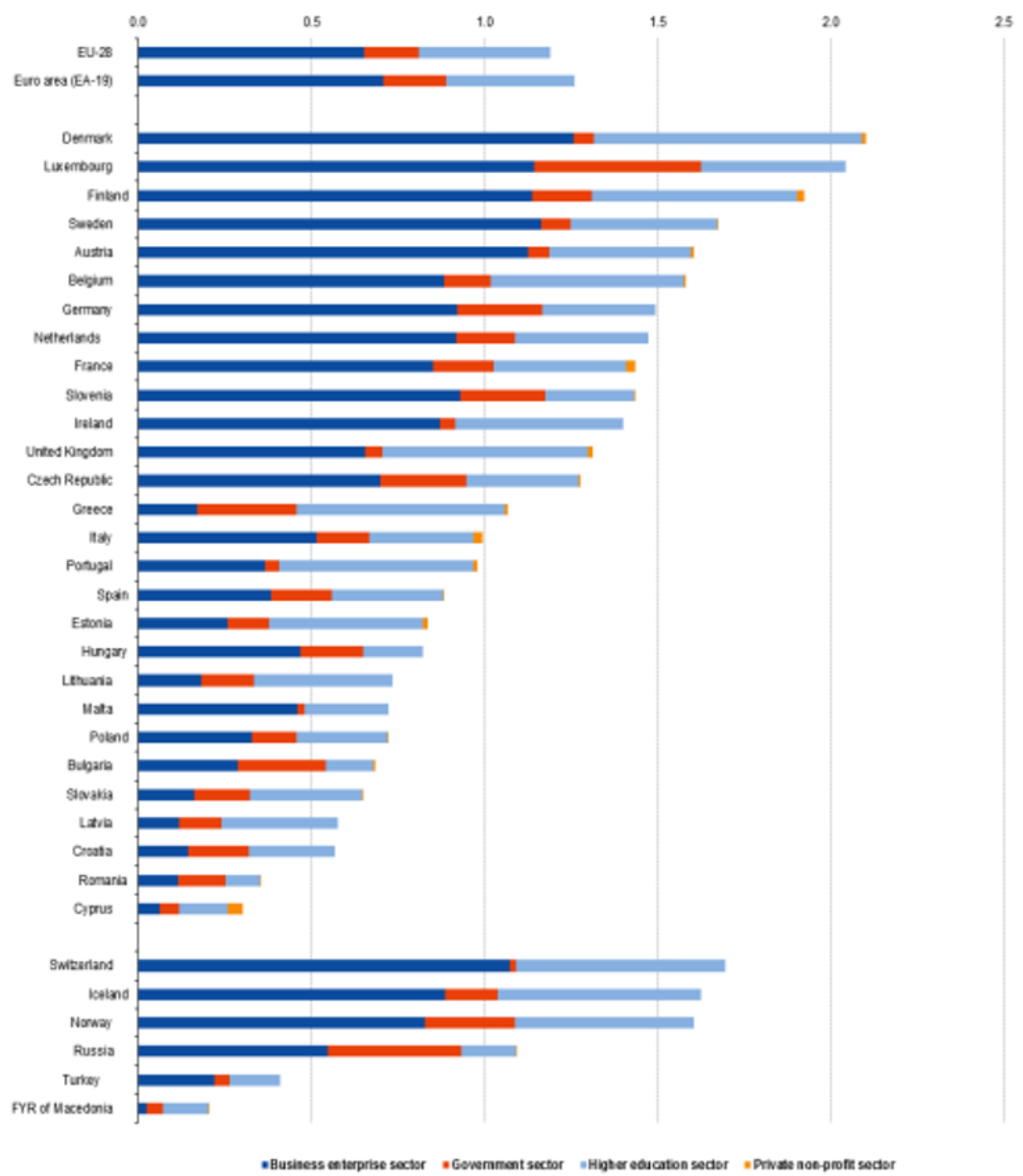

Fig. 3. Share of research and development staff in full-time equivalent, by activity sectors in 2018 (\% of the workforce). Source: Eurostat (data processed by authors).

A number of countries such as Sweden, the Netherlands, Austria, Ireland, France, 
Malta, Denmark, have seen a significant increase in the number of researchers in all these fields. In contrast to the situation in these countries, in the state sector in Bulgaria and Romania there is a significant number of researchers engaged in activity among those who have this possibility, but their total number is small compared to other states.

At the level of the European Union, 28 states, the degree of coverage in the research activity was $1.1 \%$ of the total employed labour force, and in Romania, the level of employment in the total labour force is $0.3 \%$ as in Cyprus , and in Sweden by $1.6 \%$.

Considering the four areas, namely the business sector, the higher education sector, the government sector and the private non-profit sector, we found that the largest share is employment in the business sector and then the higher education sector in these countries. In Romania we find that three fields have an important share, namely business research, research in higher education and research supported by the government, research activity in the private sector being practically insignificant.

In terms of innovation, almost half of the companies in the Member States of the European Union showed that $48.9 \%$ in the field of economic research was innovation, which represents a level of $3.9 \%$ of total researchers. About a quarter of the Member States of the European Union have organized activities in the field of innovation, with significant results that have been introduced in the field of business of economic enterprises. In the European Union as a whole, approximately $23.7 \%$ of enterprises used and introduced innovative processes both in the field of activities and in the wider field of the national economy. From this point of view we can appreciate that in the field of innovation implementation system, year by year, enterprises in various fields of activity have organized their own innovation activity, individually supported innovation or attracted innovative projects in economic activity. Also, about six out of ten innovation projects have been used efficiently, being implemented in the work of major manufacturers in each Member State.

\section{Conclusions}

This article was written by the authors on the basis of extensive research on the evolution of the economy of the Member States of the European Union in general and of each state so far, starting from the fact that there are still gaps between states, in terms of science, research and innovation. These gaps start primarily from the different level of funding for macroeconomic activity in general and science, research and innovation in particular.

The European Union aims to launch major projects to improve business in national economies so that there is a leap in economic growth. We cannot neglect the fact that this study is carried out in the context in which now the national economies of all countries around the world are deeply affected by the pandemic and economic-financial crisis, which has reduced the possibility of economic growth, reversed or distorted some correlations and proportions macroeconomic, and can speak of a destabilization that no longer takes into account the requirements of the market economy.

Another conclusion is that the European Union and the Member States, on the basis of in-depth studies, must reach solutions to allocate from the Gross Domestic Product, with priority, significantly higher amounts for the development of science, research and innovation. In some countries, Romania being one of them, it is found that the amounts allocated from the consolidated budget are smaller compared to the requirements and needs to boost the evolution of activity in these three areas or if you want elements that underlie economic development.

Another conclusion is that the evolution of improved economic growth will also ensure the unanimous desire recognized in all Member States of the European Union and worldwide for the increase in the quality of life. This is certainly easy to measure by the 
Gross Domestic Product result indicator, but it is more important to establish, using statistical-econometric models, what are the directions to go to ensure this improved quality of life.

One conclusion from the previous conclusions is that the current recovery and resilience programs must not neglect the way in which these three sides of economic development (science, research and innovation) are financed, so that we reach the discovery and realization of projects that to lead to the modernization of the economy, to the modernization of production within each country and consequently of the European Union. Nor can we neglect the fact that Cobb Douglas's production function is valid and much more relevant at the moment and must be taken into account so that the macrodestabilization that is happening at the moment is recovered by reconsidering and balancing the proportions and macroeconomic correlations. This can only be achieved through an analysis in a complex vision that starts from the fact that science, research and innovation are the essential elements that give meaning to future economic growth.

\section{References}

1. C. Anghelache, M.G. Anghel, D. Dumitrescu, D. Avram, Romania's strategy in the field of research and innovation, in the context of the European Union. Int Journ of Acad Research in Account, Fin and Manag Sciences, 8 (2), 95-101, (2018)

2. M.G. Anghel, C. Anghelache, D. Dumitrescu, Investment funds and portfolio of loan guarantees as financial steps proposals to support innovative Small and Medium Enterprises. Theoret and Appl Econ, XXIII (3) (608), Autumn, 119-126 (2016)

3. C. Anghelache, M.G. Anghel, D. Dumitru, Scientific research - determinant factor of economic development. Rom Statist Rev, Supplem, 12, 109-115 (2018)

4. C. Bravo-Ortega, A.G. Marín, R\&D and Productivity: A Two Way Avenue?. World Developm, 39 (7), 1090-1107 (2011)

5. B. Dachs, A. Pyka, What drives the internationalisation of innovation? Evidence from European patent data. Econ of Innov and New Tech, 19 (1), 71-86 (2010)

6. A.L. Maxwell et. al, Business angel early stage decision making, Journ of Business Vent, 26 (2), 212-225 (2011)

7. N. Levratto, Tessier, L. Business angels et performance des entreprises: une analyse empirique sur données françaises. Innovs, 49 (1), 141-176 (2016)

8. P. Moncada-Paternò-Castello et al, Does Europe perform too little corporate R\&D? A comparison of EU and non-EU corporate R\&D performance. Research Pol, 39 (4), 523-536 (2010)

9. A. Onetti et al, Internationalization, innovation and entrepreneurship: business models for new technology-based firms. Journ of Manag \& Gov, 16 (3), 337-368 (2012)

10. H. Pinto, The Diversity of Innovation in the European Union: Mapping Latent Dimensions and Regional Profiles. Eur Plan Stud, 17 (2), 303-326 (2009)

11. Srholec, M., Does foreign ownership facilitate cooperation on innovation? Firm-level evidence from the enlarged European Union. The Eur Journ of Develop Research, 21 (1), 47-62, (2009) 